\title{
Performance of Metal Cutting on Endmills Manufactured by Cooling-Air and Minimum Quantity Lubrication Grinding*
}

\author{
Shigeru INOUE** and Tojiro AOYAMA ${ }^{* * *}$
}

\begin{abstract}
Grinding fluids have been commonly used during the grinding of tools for their cooling and lubricating effect since the hard, robust materials used for cutting tools are difficult to grind. Grinding fluids help prevent a drop in hardness due to burning of the cutting edge and keep chipping to an absolute minimum. However, there is a heightened awareness of the need to improve the work environment and protect the global environment. Thus, the present study is aimed at applying dry grinding, cooling-air grinding, cooling-air grinding with minimum quantity lubrication (MQL), and oil-based fluid grinding to manufacturing actual endmills (HSS-Co). Cutting tests were performed by a vertical machining center. The results indicated that the lowest surface inclination values and longest tool life were obtained by cooling-air grinding with MQL. Thus, cooling-air grinding with MQL has been demonstrated to be at least as effective as oil-based fluid grinding.
\end{abstract}

Key Words: Cutting Force, Cutting Tool, Grinding Wheel, Surface Roughness, Tool Life, Tool Wear

\section{Introduction}

Cutting tools are made out of robust materials as they are used to remove undesired portions of objects made from metal and other materials. Grinding fluids are normally used during grinding to prevent burning of the cutting edge and maintain high surface quality. However, splattering of the mineral oil contained in oil-based grinding fluids and the smoke are harmful to the operators in the immediate vicinity of the machines and to the environment in general. Methods developed to alleviate these problems include cooling-air grinding, which uses no grinding fluid, and the minimum quantity lubricant (MQL) method, which uses vegetable oil ${ }^{(1),(2)}$.

Our previous study ${ }^{(3)}$ revealed that the same characteristics, such as grinding point temperature, surface roughness, post-grinding surface hardness, can be

* Received 26th November, 2004 (No. 04-4243)

** Department of Research and Development, Makino Seiki Co., Ltd., 4029 Nakatsu Aikawa-machi, Aiko-gun, Kanagawa 243-0303, Japan.

E-mail: sh-inoue@makinoseiki.co.jp

*** Department of System Design Engineering, Keio University, 3-14-1 Hiyoshi, Kohoku-ku, Yokohama-shi, Kanagawa 223-8522, Japan achieved by cooling-air grinding with or without MQL, instead of oil-based fluid grinding. The present study is aimed at applying cooling-air grinding with and without MQL to the actual endmill (material HSS-Co).

Ordinarily, an oil-based coolant is used, which often results in an eccentric shape ${ }^{(4)}$ on the relief surface. The grinding allowance for the relief surface is relatively small, but it is extremely important that the cutting edge be configured to the rake surface. Actual endmills were ground for a comparison of fluid-free grinding methods (dry grinding at room temperature and cooling-air grinding with and without MQL) with conventional oil-based fluid grinding. Then, cutting tests were performed by a vertical machining center using ground endmills. The surface roughness and inclination after milling, the cutting resistance, and the wear width on the relief surface were measured, and the results evaluated.

\section{Experimental Setup and Conditions for Grinding Endmills}

A CNJ2-30 type $\mathrm{CNC}$ tool grinding machine was used $^{(5)}$. The configuration of the machining system that combined cooling-air grinding and MQL is shown in Fig. 1. The dry compressed air discharged from the air compressor was fed to a freezer (cooling device) in order 


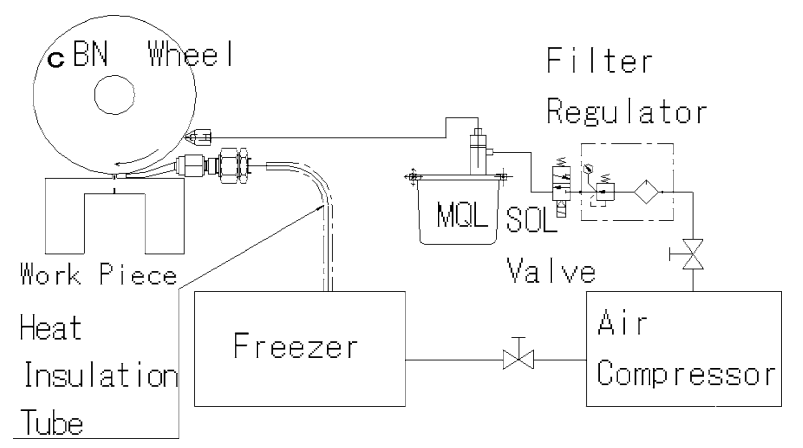

Fig. 1 Configuration of Machining System

Table 1 Main specs of the cooling device

\begin{tabular}{|c|c|}
\hline Cooling air output flow & $320 \mathrm{Nl} / \mathrm{min}$ \\
\hline Cooling air output temp & $-33^{\circ} \mathrm{C}$ \\
\hline Cooling air output pressure & $0.2 \mathrm{MPa}$ \\
\hline Electrical power & $800 \mathrm{~W}$ \\
\hline Size $(\mathrm{W} \times \mathrm{D} \times \mathrm{H})$ & $\begin{array}{l}420 \times 646 \times \\
820 \mathrm{~mm}\end{array}$ \\
\hline
\end{tabular}

to generate cooling air. Temperature rise of the cold air was minimized by using the shortest route from the cooling device to the discharge nozzle and covering the piping with heat insulation tube. A branch line from the air compressor went through a filter, regulator and solenoid valve to supply compressed air to the MQL device. This device generated mist and sprayed it on the rotating wheel surface immediately before the grinding point (immediately before cooling-air discharge nozzle). The solenoid valve could be opened and closed automatically to select or deselect MQL.

The discharge volume of the MQL device was $0.005 \mathrm{~mL}$ per cycle; at 20 cycles per minute, this amounted to a very low coolant supply of $6 \mathrm{~mL} / \mathrm{h}$.

Since this grinding work was relatively light, a largecapacity cooling device was not required. The same level of cooling capacity was used as in previous experiments ${ }^{(6)}$. The specifications of the cooling device are shown in Table 1 . In order to simplify integration of the cooling device into the grinder, a compact unit with minimal power consumption was selected.

The cooling air supply nozzle was made of copper and is shown in Fig. 2. Since the grinding width of the relief surface was less than $2 \mathrm{~mm}$, a nozzle with a crosssectional area of $3.5 \times 0.7 \mathrm{~mm}$ was assumed to be adequate. Discharge nozzle was fixed as close to the grinding point as possible. Oil-based fluid supply conditions were $50 \mathrm{~L} / \mathrm{min}$ at $0.4 \mathrm{MPa}$ pressure. On the basis of existing data ${ }^{(7)}$ these conditions were deemed necessary and sufficient for relief surfaces.

Actual relief surface grinding conditions and grinding
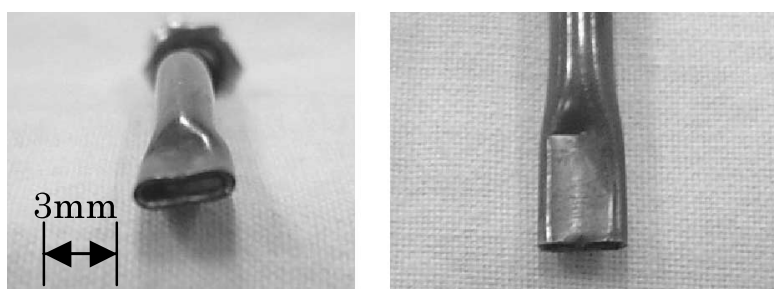

Fig. 2 Cooling air supply nozzle

Table 2 Grinding conditions and wheel specifications

\begin{tabular}{|c|c|}
\hline Material & HSS-Co \\
\hline Feed rate & $200 \mathrm{~mm} / \mathrm{min}$ constant \\
\hline $\begin{array}{l}\text { The depth of } \\
\text { cut }\end{array}$ & $0.05 \mathrm{~mm}$ constant \\
\hline Wheel speed & $30 \mathrm{~m} / \mathrm{s}$ constant \\
\hline $\begin{array}{c}\text { Wheel } \\
\text { specifications }\end{array}$ & $\mathrm{B} 270 \mathrm{~N} 100$ \\
\hline $\begin{array}{r}\text { Feed } \\
\text { direction }\end{array}$ & $\begin{array}{l}\text { Right hand helix } 30^{\circ} \\
\text { (Simultaneously } 2 \text { axes spiral) }\end{array}$ \\
\hline $\begin{array}{l}\text { Wheel size } \\
\text { (1A1 shape) }\end{array}$ & $\begin{array}{l}\phi 125(\mathrm{OD}) \times \phi 31.75(\text { Bore } \mathrm{dia}) \times \\
10 \mathrm{~mm}(\text { Width })\end{array}$ \\
\hline
\end{tabular}

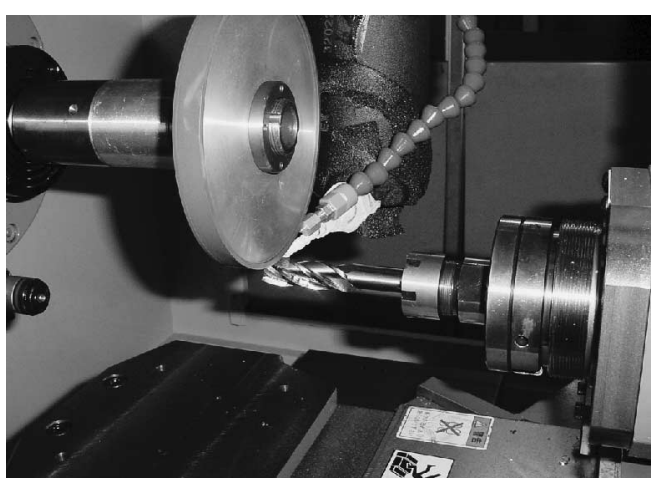

Fig. 3 Endmill grinding setup by cooling-air with MQL

wheel specifications are shown in Table 2. The grinding setup by cooling-air with MQL is shown in Fig. 3.

\section{Experimental Setup and Conditions for Metal Cutting Test}

A vertical machining center was used. The main specifications are shown in Table 3. Metal cutting tests were performed under identical cutting conditions on four kinds of endmills fabricated by four different grinding methods (dry grinding, cooling-air grinding with and without MQL grinding, and oil-based fluid grinding).

The machining setup is shown in Fig.4. A 3component dynamometer (Kistler model 9255B) was positioned on the vertical machining center table. The workpiece to be milled was mounted on the dynamometer. The workpiece was made of pre-hardened SKD61 
Table 3 Main specifications of vertical machining center

\begin{tabular}{|c|c|}
\hline CNC controlled axes & 3 axes \\
\hline $\begin{array}{c}\text { Spindle motor power } \\
\text { (continuous } / 30 \text { min rate })\end{array}$ & $7.5 / 11 \mathrm{~kW}$ \\
\hline Spindle speed (S4 digit) & $25 \sim 3500 \mathrm{~min}^{-1}$ \\
\hline $\mathrm{X} \times \mathrm{Y} \times \mathrm{Z}$ axes stroke & $1020 \times 520 \times 560 \mathrm{~mm}$ \\
\hline
\end{tabular}

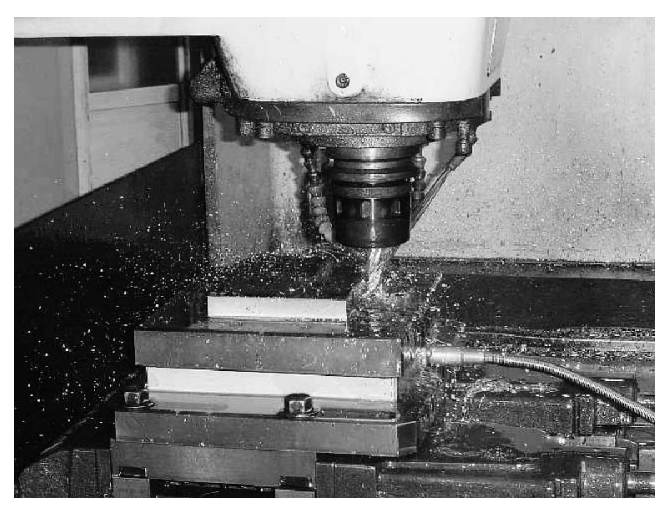

Fig. 4 Machining setup

Table 4 Cutting conditions

\begin{tabular}{|c|c|}
\hline Cutting speed & $280 \mathrm{~min}^{-1}(14 \mathrm{~m} / \mathrm{min})$ \\
\hline Cutting width & $16 \mathrm{~mm}$ \\
\hline Depth of cut & $1.6 \mathrm{~mm}$ \\
\hline Feed & \multicolumn{2}{|c|}{$90 \mathrm{~mm} / \mathrm{min}(0.08 \mathrm{~mm} /$ teeth $)$} \\
\hline Up or Down cut & $\begin{array}{l}\text { X axis ( Table longitudinal ) } \\
\text { direction Down cut }\end{array}$ \\
\hline
\end{tabular}

(HRC35) and its dimensions were $170 \mathrm{~mm}$ (width) $\times$ $140 \mathrm{~mm}$ (depth) $\times 25 \mathrm{~mm}$ (height). The cutting conditions are shown in Table 4. Oil-based fluid (Yushiro type UH75) milling is performed using endmills manufactured to the following specifications: outer diameter $16 \mathrm{~mm}, 4$ teeth, rake angle $15 \mathrm{deg}$, relief angle $10 \mathrm{deg}$, concentricity $15 \mu \mathrm{m}$ or less. Assessment endmill life is based on the relationship between the cutting length and the wear width on the relief surface of the endmills.

\section{Results and Observations}

\subsection{The wear width on the relief surface of end- mills and cutting resistance}

The relation between the wear width on the relief surface and cutting length is shown in Fig. 5. The relationship between the wear width on the corner relief surface (i.e., at the meeting point between the outer cutting edge and end teeth) and cutting length is shown in Fig. 6. In general, the wear width on the relief surface increased with cutting length, as shown in Fig. $5^{(8)-(11)}$. A cutting length of $0.2,2.0$, and $4.1 \mathrm{~m}$ corresponds to what will hereinafter

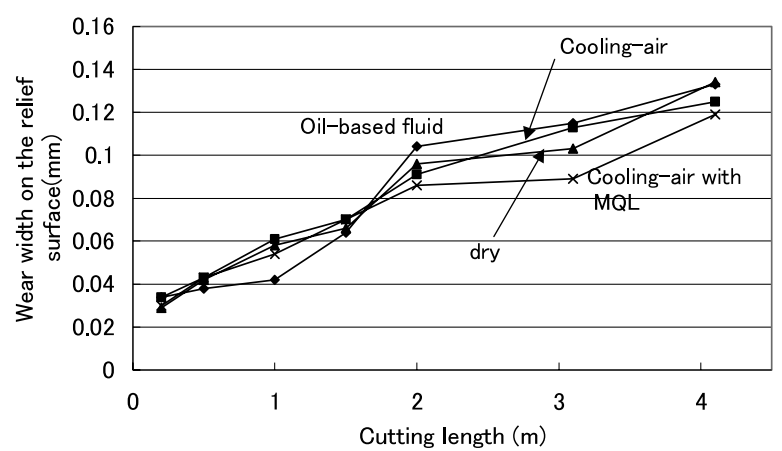

Fig. 5 Wear width on the relief surface vs. cutting length

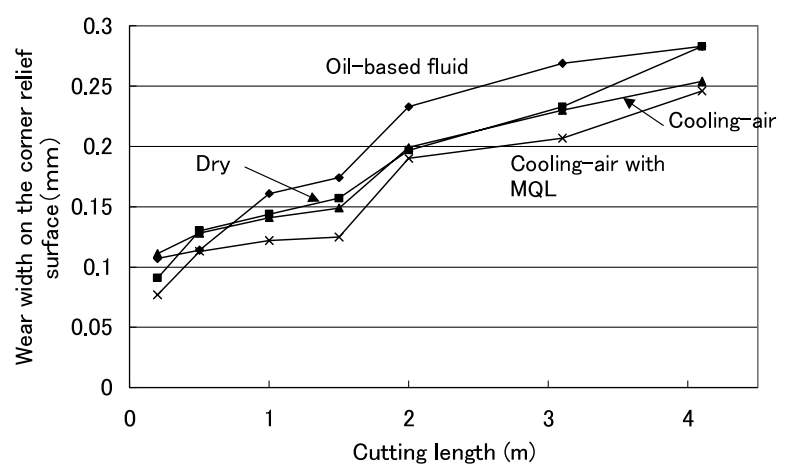

Fig. 6 Wear width on the corner relief surface vs. cutting length

be referred to as the initial, middle, and final stage cutting, respectively.

The wear width on the relief surface of the endmill in the case of oil-based fluid grinding showed a minimum value at a cutting status between the initial and middle stages. However, after the middle stage, dry grinding and cooling-air grinding yielded almost the same wear width on the relief surface as oil-based fluid grinding. After the middle stage, the wear width on the relief surface was the lowest in the case of cooling-air grinding with MQL.

The wear width on the corner relief surface also increased with cutting length. The wear width on the corner relief surface was about twice the wear width on the relief surface. This is thought to be due to the simultaneous outer diameter cutting and end cutting, causing severe cutting conditions at the corner relief point ${ }^{(12)}$. In oil-based fluid grinding, the wear width on the corner relief surface increased rapidly above a cutting length of $1 \mathrm{~m}$. But similar values were observed in dry grinding during the final stage cutting. Overall, cooling-air grinding with MQL yielded the lowest values of wear width on the relief surface.

Figures 7-9 show the wear on the relief surface for oil-based fluid grinding and cooling-air grinding with MQL following the initial, middle, and final stages, respectively (In each case, all four teeth were shown). The endmill processed by oil-based fluid grinding exhibited a round-shaped wear on the corner relief surface and microchipping on the cutting edge, while the endmill ground 
(Oil-based fluid)

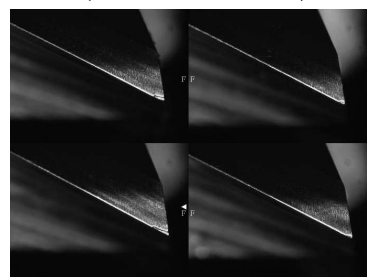

Wear width $0.107 \mathrm{~mm}$
(Cooling-air with MQL)

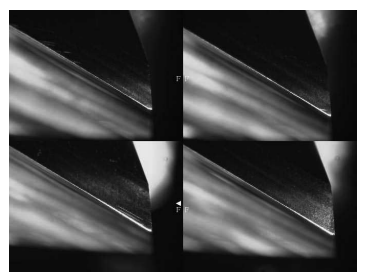

Wear width $0.077 \mathrm{~mm}$

Fig. 7 The wear width on the corner relief surface in the initial stage of cutting

(Oil-based fluid)

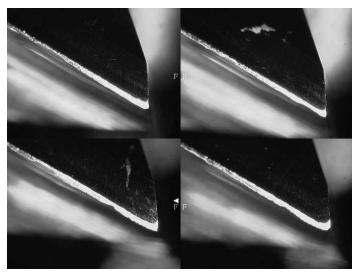

Wear width $0.233 \mathrm{~mm}$
(Cooling-air with MQL)

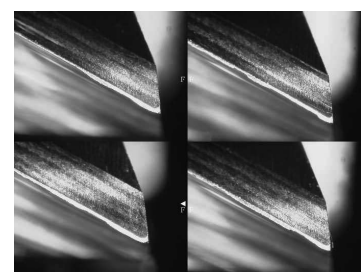

Wear width $0.190 \mathrm{~mm}$

Fig. 8 The wear width on the corner relief surface in the middle stage of cutting

(Oil-based fluid)

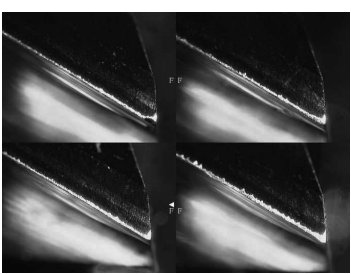

Wear width $0.283 \mathrm{~mm}$
(Cooling-air with MQL)

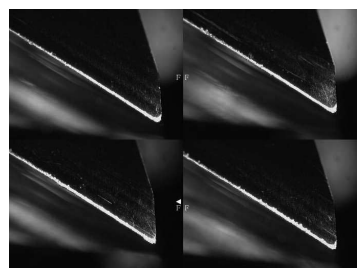

Wear width $0.246 \mathrm{~mm}$

Fig. 9 The wear width on the corner relief surface in the final stage of cutting

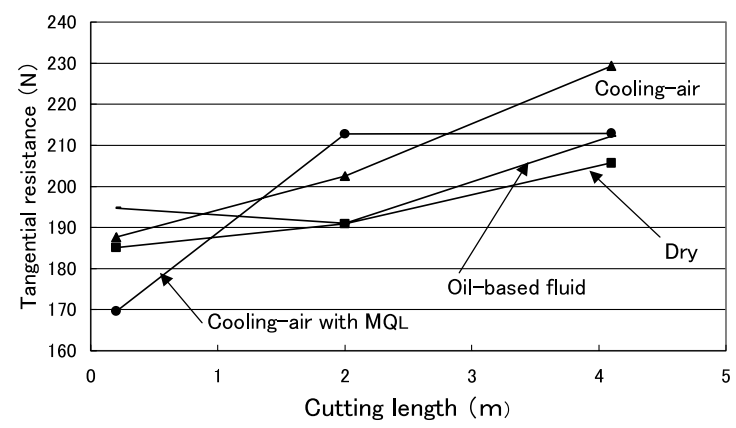

Fig. 10 Tangential resistance vs. cutting length

using cooling-air with MQL was nearly uniform over the sharp, four tooth cutting edge.

Maximum cutting resistance values were measured by the 3-component dynamometer (Kisler Model 9255B). Figures 10-12 show the cutting resistance for four different endmills as a function of cutting length in the tangential, normal and feed directions, respectively. In general, the cutting resistance increased slightly with cutting length

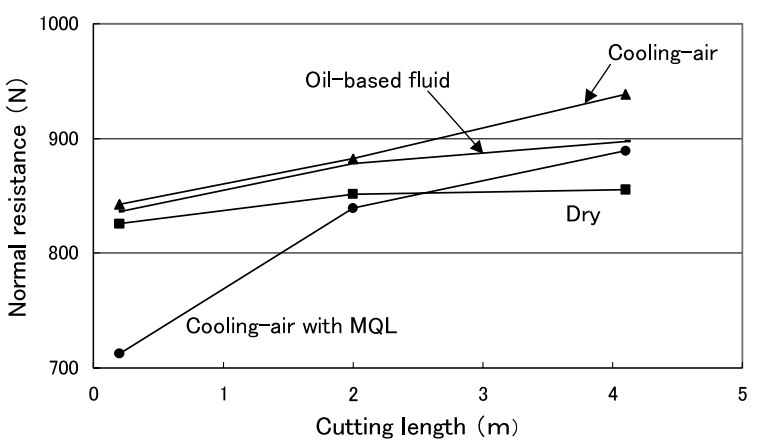

Fig. 11 Normal resistance vs. cutting length

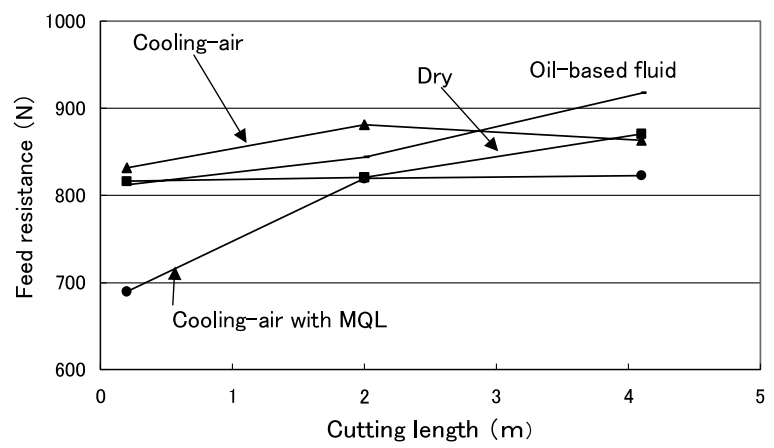

Fig. 12 Feed resistance vs. cutting length

due to the increase in the wear on the cutting edge ${ }^{(13),(14)}$. Figures 10-12 show the cutting resistances during the initial stage. In the case of cooling-air grinding with MQL, the cutting resistance values were $689.49,702.39$, and $169.6 \mathrm{~N}$ in the feed, normal, and tangential directions, respectively. These represented the lowest values among the four types of endmills because the most effective cutting was achieved by cooling-air grinding with MQL. There were no other significant differences between the plots in Figs. 10-12.

\section{2 Milled surface roughness and inclination}

Milled surface roughness was measured by a surface roughness profilometer (Feinpruf Model S6P). Figures 13 and 14 show the milled surface roughness as a function cutting length for the four endmills in the feed and axial directions, respectively.

In general, the surface roughness decreases from the initial to the middle cutting stage since an identical cutting performance is obtained on all four cutting edges after the initial wear caused by a concentricity error in the endmills. Dry grinding produced the lowest and highest surface roughness in the initial and final stages, respectively.

The surface roughness values for cooling-air grinding with MQL differed greatly from those for cooling-air grinding without MQL, the values were almost the same as those obtained after the final stage of the other case. In addition, these values were relatively lower than those for oil-based fluid grinding. 


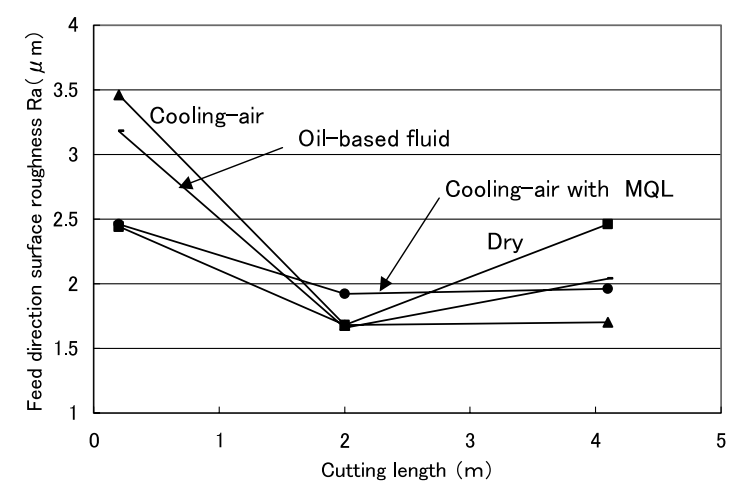

Fig. 13 Feed direction surface roughness vs. cutting length

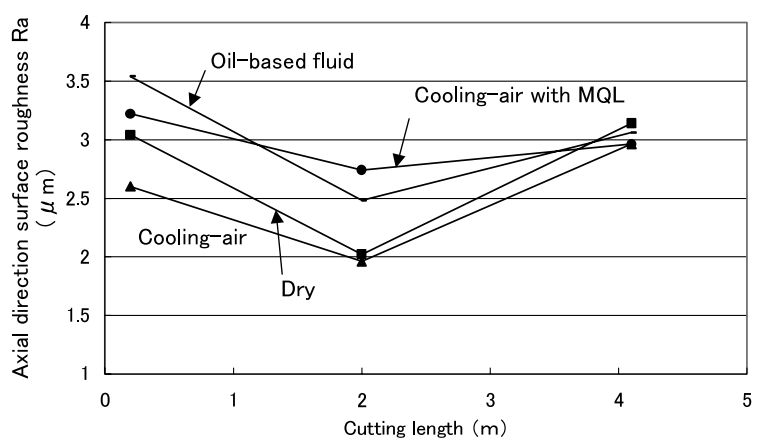

Fig. 14 Axial direction surface roughness vs. cutting length

For milling surface inclination measurements, an electrical micrometer (TESA Model TTA20) located on the spindle head of the machining center was moved up and down by a CNC motion system. The data from the electric micrometer were transferred through an amplifier and recorded on pen-recorder ${ }^{(15)}$. Evaluation of the measurement is based on the absolute value of the difference (maximum data - minimum data).

The actual data for cooling-air grinding with MQL is shown in Fig. 15. The relationship between the milled surface inclination and the cutting length are shown in Fig. 16.

For all endmills, the milled surface inclination decreased from the initial to the middle stage since an identical cutting performance is obtained on all cutting edges after the initial wear. Subsequently, all surface inclination values increased in the final stage. These trends exactly match those observed for milled surface roughness. The milled surface inclination was the lowest for cooling-air with MQL regardless of the cutting stage.

\section{Conclusion}

Metal cutting tests were performed under identical conditions using four endmills that were ground by four different grinding methods, namely, dry grinding, coolingair grinding with or without MQL and oil-based fluid grinding.

The results are summarized as follows:

(1) The wear width on the relief surface showed a

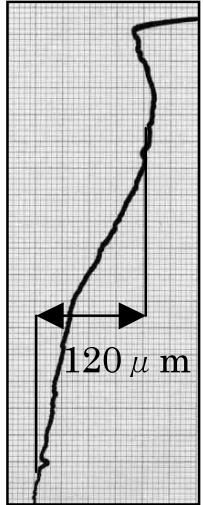

Initial

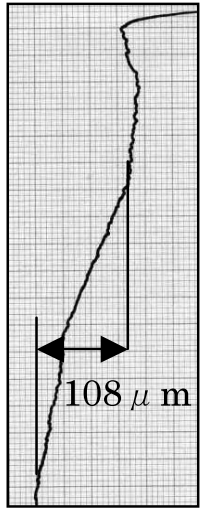

Middle

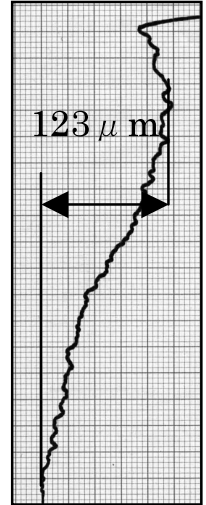

Final
Fig. 15 Measurement data on the milled surface inclination (cooling-air with MQL)

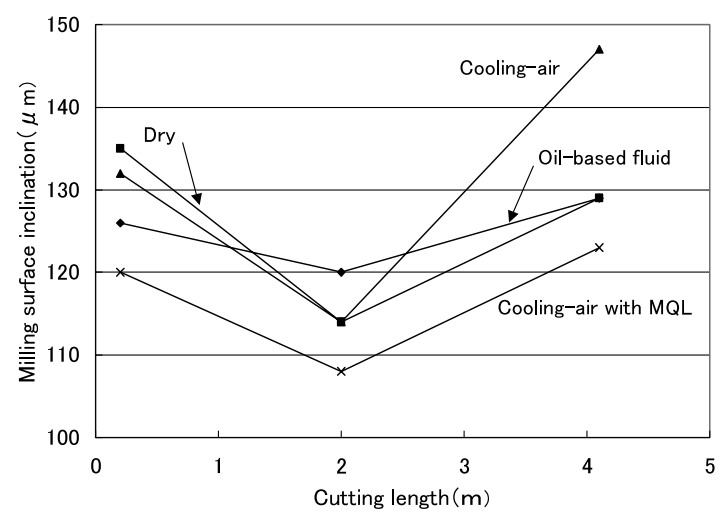

Fig. 16 Milled surface inclination vs. cutting length

minimum in the case of cooling-air grinding with MQL. An evaluation of the tool life for the wear width on the corner relief surface revealed that, for a wear width on the relief surface of less than $0.2 \mathrm{~mm}$, a cutting length of $2.6 \mathrm{~m}$ was obtained, which represents the longest tool life among the four different endmills.

(2) Examination of the wear on the corner relief surface after the cutting test revealed that, the endmill ground by cooling-air with MQL remained nearly uniform over the shape, four tooth cutting edge.

(3) The milled surface roughness in the case of cooling-air grinding with and without MQL yielded almost the same values as the other case in the final stage. These values are lower than those for oil-based fluid grinding.

( 4 ) For each cutting stage, the milled surface inclination was the lowest in the case of cooling-air grinding with MQL.

While relief surface tool grinding involves relatively light work, a high surface quality is required, and thus, endmills are often manufactured using oil-based fluid grinding. This study demonstrates, however, that the same characteristics, such as cutting resistance, cutting edge 
quality, milled surface roughness and post-grinding surface inclination, can be achieved by cooling-air grinding with MQL.

\section{References}

( 1 ) Saito, Y., Machine Tool Engineering for Environmental Awareness, Jpn. Soc. Abr. Tec., (in Japanese), Vol.43, No.1 (1999) pp.5-9.

(2) Yokogawa, M., Trend of Environment-Friendly Machining Europe and Japan, Jpn. Soc. Abr. Tec., (in Japanese), Vol.43, No.1 (1999), pp.14-17.

( 3 ) Inoue, S. and Aoyama, T., Application of Air Cooling Technology and Minimum Quantity Lubrication to Relief Grinding of Cutting Tools, Advances in Abrasive Technology IV, (2003), pp.345-350.

( 4 ) Jpn. Soc. Pre. Eng., Precision Engineering Hand Book, (in Japanese), (2000), pp.429-430, Nikkan Kogyo.

( 5 ) Inoue, S., Recent Technology of CNC Tool Grinding Machine, Tool Engineer., (in Japanese), Vol.40, No.6 (1996), pp.45-49.

( 6 ) Honma, H., Yokogawa, K. and Yokogawa, M., Study on Environment Conscious cBN Cooling Air Grinding Technology, Jpn. Soc. Pre. Eng., (in Japanese), Vol.62, No.11 (1996), pp.1638-1642.

( 7 ) Inoue, S., Actual Grinding Technique on CNC Tool Grinder, Jpn. Soc. Pre. Eng., (in Japanese), (1985), pp.185-194.
( 8 ) End Mills, (in Japanese), (1991), pp.128-129, Taiga Syuppan.

( 9 ) Fujii, Y. and Iwabe, H., Fluctuation of Work Accuracy Due to Flank Wear of End Mills, Jpn. Soc. Pre. Eng., (in Japanese), Vol.46, No.8 (1980), pp.1015-1020.

(10) Matsumura, T., Murayama, T. and Usui, E., Tool Wear Monitoring System in Milling Operation, Jpn. Soc. Pre. Eng., (in Japanese), Vol.65, No.11 (1999), pp.16171622.

(11) Lu, Y., Takeuchi, Y., Mitsumori, M., Takahashi, I., Kase, K. and Anzai, M., Fabrication of Ball End Mills for High Speed Milling and Their Cutting Characteristic, Jpn. Soc. Pre. Eng., (in Japanese), Vol.68, No.3 (2002), pp.451-455.

(12) Usui, E., Cutting and Grinding Technology (1), (in Japanese), (1974), pp.279-280, Kyoritsu Syuppan.

(13) Tanaka, Y., Tsuwa, H. and Ikawa, N., Precision Machining Method (2), (in Japanese), (1982), pp.78-79, Kyoritsu Syuppan.

(14) Mutou, M., Morita, N. and Yoshida, Y., Study on High-Speed Milling of Hard Materials (2nd Report) Effect of Tool Shape on Cutting Force, Cutting Edge Temperature and Tool Wear-, Jpn. Soc. Pre.Eng., (in Japanese), Vol.65, No.2 (1999), pp.234-239.

(15) End Milling Operations, OSG Catalogue, (1991), pp.41-42. 